\title{
Phytochemical and Anti-Inflammatory Evaluation of Herbal Gel Prepared from Bark Extract of Mesua Ferrea Linn
}

\author{
Harjeet Singh ${ }^{1 *}$, B. K. Sarkar1, Jagdish Chandra Arya ${ }^{1}$, Shashi Pal2, Ravi Kumar ${ }^{3}$, Veerendra \\ Gupta $^{1}$, Ravindra Singh ${ }^{4}$, S. C. Verma ${ }^{5}$ \\ ${ }^{1}$ Regional Ayurveda Research Institute, Gwalior Road, Jhansi, UP-284003, India. \\ ${ }^{2}$ Assistant Professor, Career Point University, Hamirpur, HP, India. \\ ${ }^{3}$ Central Ayurveda Research Institute for Respiratory Disorders, Moti Bagh Road, Patiala, Punjab, India. \\ ${ }^{4}$ CCRAS, Ministry of AYUSH, Govt. of India, New Delhi-110058, India. \\ 5 Pharmacopoeial Laboratory for Indian Medicine (PLIM) Ghaziabad, UP, Ministry of AYUSH, Govt. of India), India.
}

\section{ABSTRACT}

The present research work involves formulation of herbal gel containing stem bark extracts of Mesua ferrea Linn and its evaluation for in vitro anti-inflammatory activity. The gel formulations were prepared using ethanolic extracts along with different polymer. The physiochemical parameters of formulations like; pH, viscosity and spreadability etc. also evaluated. Phytochemical analysis revealed presence of phenols, flavonoids and alkaloids, etc. The ethanolic extracts showed appreciable anti-inflammatory activity compared to the standard drug. Study confirmed that potential anti-inflammatory formulation can be developed from bark extract of Mesua ferrea Linn.
\end{abstract}

Keywords: Mesua ferrea Linn., Anti-inflammatory, Herbal Gel, Phytochemical, Albumin denaturation.

Article Info: Received 19 July 2019; Review Completed 12 Aug 2019; Accepted 27 Aug 2019; Available online 15 Oct 2019

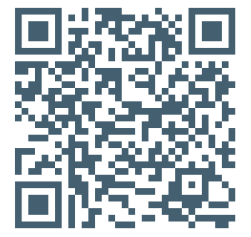

\section{Cite this article as:}

Singh H, Sarkar BK, Arya JC, Pal S, Kumar R, Gupta V, Singh R, Verma SC, Phytochemical and Anti-Inflammatory Evaluation of Herbal Gel Prepared from Bark Extract of Mesua Ferrea Linn, Journal of Drug Delivery and Therapeutics. 2019; 9(5s):53-56 http://dx.doi.org/10.22270/jddt.v9i5-s.3638

Harjeet Singh, Regional Ayurveda Research Institute, Gwalior Road, Jhansi, UP-284003, India.

\section{INTRODUCTION}

Inflammation is a body response that acts as an protective mechanism and induces as a resultant of injury. The symptoms of inflammation are redness, swelling and pain, while chronic conditions of inflammation may induces pathogenesis of disease like; arthritis. Vasodilatation, increased permeability of capillary and leukocytes migration these are some biological responses that are associated with inflammation $[1,2]$.

Generally non-steroidal anti-inflammatory drugs (NSAIDs) are used to control inflammation; however these drugs suffer some disadvantages like; gastric irritation and renal dysfunction. Therefore it is required to develop some naturally originated drugs as anti-inflammatory agents which can overcome adverse effects of classical NSAIDs.

Mesua ferrea Linn. is a plant of medicinal importance belongs from family Clusiaceae distributed around countries like Burma, India, Indochina and Thailand. Mesua ferrea used for various medicinal purposes [3-5] like; treatment of inflammation, ulcers, hemorrhoids, wounds and piles. Bark of plant used as astringent, also used for bronchitis and gastritis. Plant traditionally recommended for diseases associated with pain and inflammation. Considering above mentioned aspects present study was planned for the phytochemical and pharmacological evaluation of gel prepared from Mesua ferrea.

\section{MATERIALS AND METHODS}

Ethanol, Folin-ciocalteu reagents and albumin were purchased from Loba Chem. All other chemicals and reagents used were of analytical grade. The stem bark of Mesua ferrea Linn. was collected from the local forest area of Karnataka state of India. Stem bark was first washed with running water to remove dirt and other waste materials, after that it was rinsed with distilled water and dried under shade for extraction purpose.

\section{Extraction of the plant material}

The bark of Mesua ferrea was dried under shade and pulverized in a mechanical grinder into coarse powder. The dried powder first passed through sieve no. 40 to optimize uniformity then 500 gm of dried powder was subjected to extraction using soxhlet apparatus. Extracts were 
concentrated to dryness using rotary evaporator and stored in desiccator to avoid any moisture content [6].

\section{Phytochemical studies}

The preliminary phytochemical analysis was performed using methods described earlier with slight modification [7, 8]. The phytochemical analysis was performed to confirm presence of phytoconstituents such as flavonoids, alkaloids, phenols, saponins, glycosides and tannins, etc.

\section{Quantitative analysis of extracts}

\section{Total phenol content:}

Total phenol content in extract was determined using FolinCiocalteu method, about $1 \mathrm{ml}$ of $100 \mu \mathrm{g}$ of extracts was mixed with $2 \mathrm{ml}$ of Folin-Ciocalteu reagent (previously diluted up to $1: 10, \mathrm{v} / \mathrm{v}$ ). The mixture was allowed to stand for $90 \mathrm{~min}$. at room temperature after addition of $2 \mathrm{ml}$ of sodium carbonate solution $(7.5 \% \mathrm{w} / \mathrm{v})$. Absorbance was measured after incubation period against the blank at $750 \mathrm{~nm}$ using UV-visible spectrophotometer (Shimadzu) [9].

\section{Determination of total flavonoids content}

Total flavonoid content of extract was determined as per the method described by Zhishen et al., [10] with slight modification. About $2.5 \mathrm{ml}$ of $100 \mu \mathrm{g}$ of extract was added in a mixture of $300 \mu \mathrm{l}$ of $5 \%$ sodium nitrite and $300 \mu \mathrm{l}$ of $10 \%$ aluminum chloride. Sodium hydroxide (2 $\mathrm{ml}$ of $1 \mathrm{M}$ ) was added after the incubation of mixture for $6 \mathrm{~min}$. at room temperature. Absorbance was measured at $510 \mathrm{~nm}$ using UV-visible spectrophotometer (Shimadzu).

\section{Preparation of Herbal Gel}

The gel formulations of herbal extract was prepared using the compositions depicted in Table 1. First purified water containing sodium benzoate soaked in carbapol. HPMC/Sodium Alginate solution was prepared and homogenized separately. The drug solution was transferred to HPMC/Sodium Alginate solution followed by homogenization; that after this solution containing drug \& polymer added to the previously prepared carbapol solution and finally neutralized using triethanolamine followed by homogenization to obtain gel formulation of uniform consistency $[11,12]$.

Table 1: Composition of Herbal Gel Formulations (\%w/w):

\begin{tabular}{|l|c|}
\hline Ingredients & $\begin{array}{c}\text { Gel prepared from ethanolic } \\
\text { extracts }\end{array}$ \\
\hline HPMC & 1 \\
\hline Carbapol & 1 \\
\hline Sodium Alginate & 1 \\
\hline Drug extract & 4 \\
\hline Propylene Glycol & 6 \\
\hline Sodium benzoate & 0.3 \\
\hline Triethanolamine & As required (up to neutralization) \\
\hline Distilled Water & q.s. \\
\hline
\end{tabular}

\section{Evaluation of gel formulations $[11,12]$ \\ Physical evaluation}

Color, appearance and consistency were observed as physical parameters. The typical gel like appearance was considered as standard formulations.

\section{pH Measurement}

$\mathrm{pH}$ of the formulations were measured using digital $\mathrm{pH}$ meter which was calibrated previously using standard buffer solutions meant for $\mathrm{pH}$ calibration.

\section{Spreadibility}

Spreadibility was measured using an apparatus that involve a wooden block along with a pulley at one end. The slip and drag characteristics of gels were utilizes to measure spreadibility. There are two slides in apparatus one is ground slide while another one is fixed slide that is attached with a hook. Excess amount of gel formulation was applied between two slides and weight around $1 \mathrm{~kg}$ was applied for 5 minutes to obtain a uniform film of gel between the slides. Excess amount of gel was scrapped out from the edges of slides and top slide was pulled off with the help of hook and time in seconds was noted down required by the slide to cover a fix distance. Spreadibility was calculated using the following formula:

$$
\mathrm{S}=\mathrm{M} \times \mathrm{L} / \mathrm{T}
$$

Where, $\mathrm{S}=$ Spreadibility, $\mathrm{M}=$ Weight in the pan, $\mathrm{L}=$ Length moved by the glass slide, $\mathrm{T}=$ Time (sec.) required for separation of slides.

\section{Homogeneity}

The herbal gel formulation was tested for homogeneity by visual inspection; it is done by inspecting gel formulation for their consistent appearance and presence of aggregates.

\section{Viscosity}

Viscosity of gel formulation was measured using Brookfield viscometer fitted with spindle. The instrument measures shear stress that applied on a spindle rotating at a constant speed when placed in the sample solution.

\section{Analytical Standardization}

\section{Thin Layer Chromatography (TLC)}

Silica gel G60F254 was used as stationary phase; the plates were developed in twin trough glass chamber using ascending method. The sample solution was prepared by dissolving dry extract in ethanol. The sample solution was applied as bands using $100 \mu \mathrm{l}$ syringe maintaining $2 \mathrm{~cm}$ distance from the bottom of the plate.

\section{Infra-red spectroscopy (IR)}

The IR spectrum of ethanolic extract was scanned on FT-IR spectrophotometer over the range of $4000-400 \mathrm{~cm}^{-1}$.

\section{Inhibition of albumin denaturation}

The preliminary in vitro anti-inflammatory activity of Mesua ferrea extract was performed using "inhibition of albumin denaturation" method [13]. The test solution consisted of extracts with $1 \%$ aqueous solution of albumin, $1 \mathrm{~N} \mathrm{HCl}$ was used to adjust the $\mathrm{pH}$ of reaction mixture. The solutions were incubated at $37^{\circ} \mathrm{C}$ for $20 \mathrm{~min}$. followed by heating at $51^{\circ} \mathrm{C}$. Turbidity was measured at $660 \mathrm{~nm}$ after cooling the samples solution. Inhibition of albumin denaturation was calculated as anti-inflammatory response of extracts using the following formula:

\section{Percent inhibition $=[(A c-A t) / A c] \times 100$}

Where "Ac" is absorbance of control (solvent) and "At" is the absorbance of test solution (extract).

\section{RESULTS AND DISCUSSION}

The qualitative screening of extract confirms presence of phenols, alkaloids, tannins and glycosides (Table 2). The total phenolic and flavonoids contents were found to be $59.7 \mu \mathrm{g} / \mathrm{ml}$ and $9.0 \mu \mathrm{g} / \mathrm{ml}$ respectively in plant extract. 
Table 1: Qualitative and quantitative chemical analysis:

\begin{tabular}{|c|c|c|c|}
\hline \multicolumn{2}{|c|}{ Qualitative test } & \multicolumn{2}{c|}{ Quantitative chemical analysis } \\
\hline Test performed for & Present (+)/Absent(-) & Test performed for & Amount found $(\boldsymbol{\mu g} / \mathbf{m l})$ \\
\hline Flavonoids & + & Total Phenols & 59.7 \\
\hline Alkaloids & + & Total Flavonoids & \\
\hline Phenols & + & \\
\hline Saponins & + & \\
\hline Glycosides & + & \\
\hline Tannins & + & \\
\hline
\end{tabular}

The gel formulation was prepared by trial \& error method. Initially concentrations of polymer varied many times to developed optimized formula and finally herbal gel was prepared using composition mentioned in table 1.

The physical test revealed that gel formulation is light brown in color and having translucent appearance. Gel was found good in homogeneity without any lumps, the spreadability observed within acceptable range which indicated that gel formulation is spreadable even by small amount of shear. The $\mathrm{pH}$ of formulation was found to be slightly neutral side which is prerequisite for topical gel like preparation. Viscosities of formulation along with other parameter reported in Table 3.

Table 4: Evaluation of herbal gel prepared from ethanolic extracts of Mesua ferrea.

\begin{tabular}{|c|l|c|}
\hline S. No. & \multicolumn{1}{|c|}{ Parameters } & Results \\
\hline 1 & Color & Light brown \\
\hline 2 & Appearance & Translucent \\
\hline 3 & pH & 6.7 \\
\hline 4 & $\begin{array}{l}\text { Spreadibility } \\
\text { (gm. cm./ sec) }\end{array}$ & 29.35 \\
\hline 5 & Homogeneity & Homogenous \\
\hline 6 & Viscosity (cps) & 1538 \\
\hline
\end{tabular}

The analytical standardization was performed using chromatographic and spectral techniques. Thin layer chromatography was performed as chromatographic method to separate out important phytoconstituents from herbal extract. The combination of solvents; Ethyl acetate: methanol: formic acid (7: 2.5: $0.5 \mathrm{v} / \mathrm{v} / \mathrm{v}$ ) was used as mobile phase and separated chromatogram were observed at $\mathrm{R}_{\mathrm{f}}$ value above 0.25 as mentioned in Figure 1.

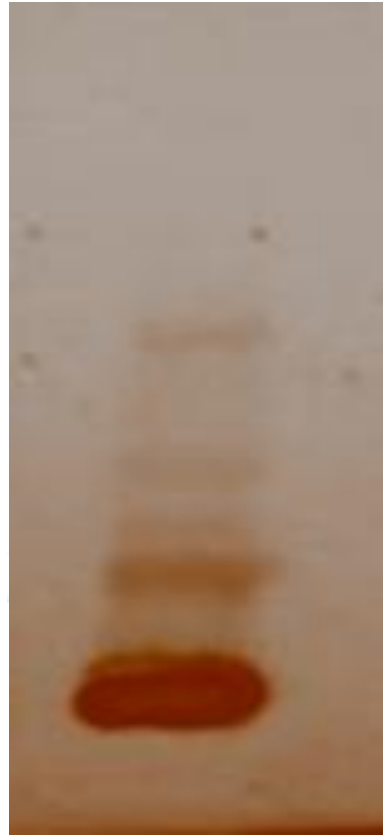

Figure 1: TLC profile of extract of Mesua ferrea

IR spectroscopy was performed as spectral technique of analysis and IR spectra of plant extract recorded at range 4000-400 cm-1, spectra confirmed the presence of characteristic peaks of important phytoconstituents like; alkaloid, phenols and flavonoids, etc. The IR spectra also revealed characteristic overtone of aromatic compound which indicates presence of aromatic ring in herbal extract (Figure 2).

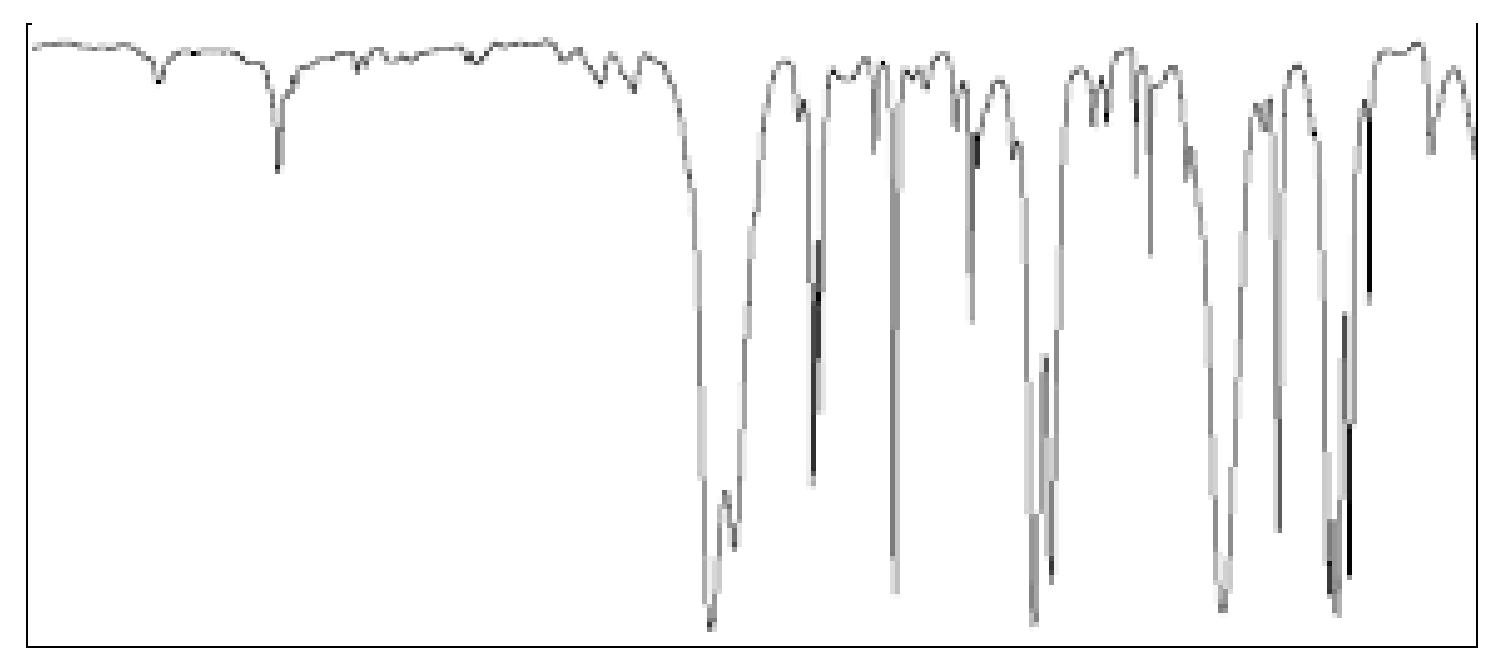

Figure 2: IR spectra of extract of Mesua ferrea. 
The in vitro anti-inflammatory activity was performed to ascertain pharmacological profile of extract of Mesua ferrea. The inhibition of albumin denaturation was performed as a measure of anti-inflammatory potential of test compound. The inhibition of protein denaturation was observed in dose dependent manner and maximum activity was observed with higher concentration of extract $(500 \mu \mathrm{g} / \mathrm{ml})$. The extract at concentration level $500 \mu \mathrm{g} / \mathrm{ml}$ exerted $79 \%$ inhibition of protein denaturation which was found to be comparable to the standard drug Diclofenac sodium (Figure 3).

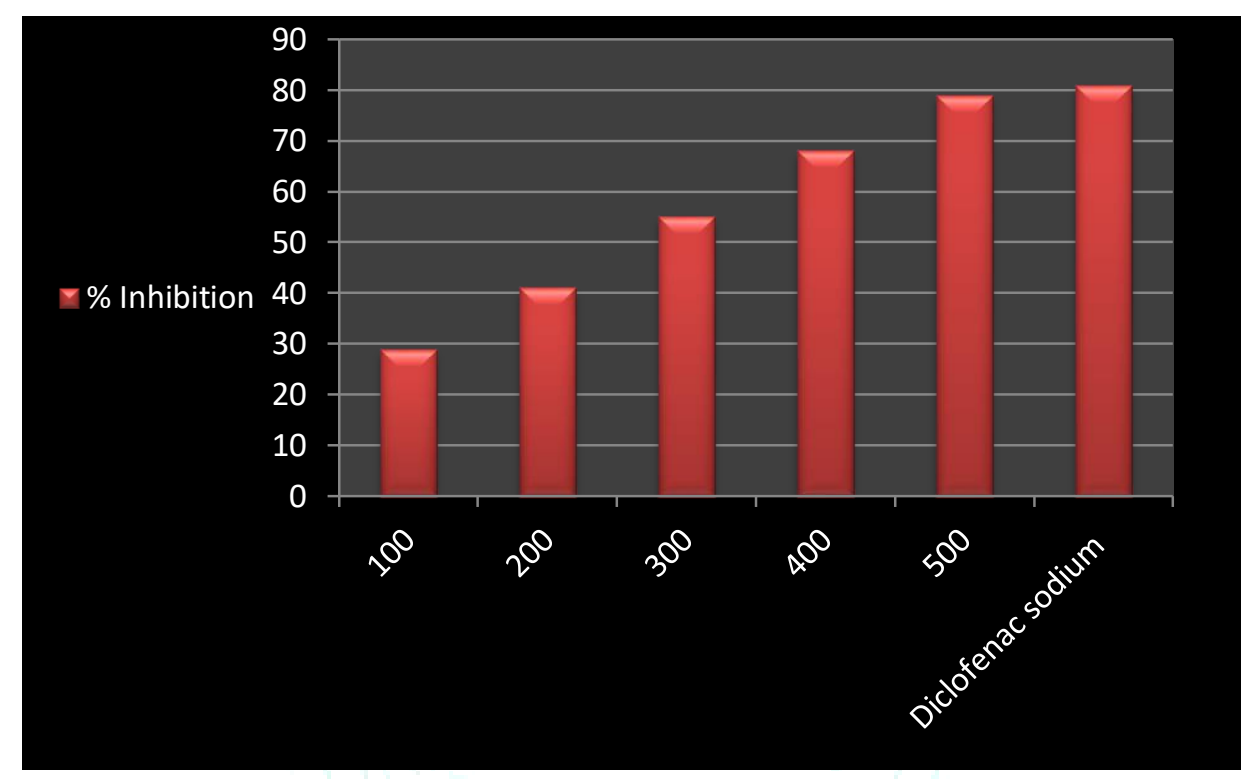

Figure 3: In vitro anti-inflammatory activity of extract of Mesua ferrea (\%inhibition of albumin denaturation).

\section{CONCLUSION}

Study revealed that developed herbal formulation consisting extract of Mesua ferrea possesses most of the desired properties of topical formulation. Study concluded that $M$. ferrea Linn. offers appreciable anti-inflammatory activity and this response can be attributed to the presence of phtoconstituents like; alkaloids, flavonoids and tannins, etc. The study support folkloric use of $M$. ferrea as antiinflammatory agent. However further study on animal population is required to confirm mechanisms of antiinflammatory potential of plant extract, additionally it is also required to identify active constituents responsible for antiinflammatory activity of $M$. ferrea bark extract. Study suggests that gel formulation prepared from bark extract of Mesua ferrea can be employed as topical anti-inflammatory agent for various therapeutic purposes.

\section{REFERENCES}

1. Nathan C. Points of control in inflammation. Nature 2002; 26:846-52.

2. Vonkeman HE, van de Laar M. Non-steroidal antiInflammatory drugs: adverse effects and their prevention. Semin Arthritis Rheum 2010; 39:294-312.

3. Manoj Kumar Chahar, Sanjaya Kumar DS, Geetha L, Lokesh T, Manohara KP. Mesua ferrea L. A review of the medical evidence for its phytochemistry and pharmacological actions. Afr J Pharm Pharmacol 2013;7:211-9.
4. Manjunath BK, Syed murtuza, Divakara, Archana, Sarvani, Steffina, et al. Antioxidant and anti-inflammatory potency of Mesua ferrea Linn. Indian J Appl Res 2013;8:3.

5. Vandana Rawat, Kumud Upadhyaya. Evaluation of antimicrobial activity and preliminary phytochemical screening of Mesua ferret seeds extract. Indian J Nat Prod 2013;6:17-26.

6. Harborne JB. Phytochemical methods, A guide to modern techniques of plant analysis, Spring Publisher, 2008, 40-96, 107-138, 151-179, 235-249.

7. Harborne JB. Phytochemical methods: a guide to modern techniques of plant Analysis. 3rd ed. London: Chapman and Hall; 1988. p. 117.

8. Trease GE, Evans WC. Pharmacognosy. 12th ed. ELBS Publication, Baillier Tindall, East Bourne; 1996. p. 539.

9. Chang C, Yang M, Wen H, Chern J. Estimation of total flavonoid content in propolis by two complementary colorimetric methods. J Food Drug Anal 2002;10:178-82.

10. Zhishen J, Mengcheng $\mathrm{T}$, Jianming $\mathrm{W}$. The determination of flavonoid content in mulberry and their scavenging effects on superoxide radicals. Food Chem 1999; 64:555-9.

11. Kumar L, Verma R. In vitro evaluation of topical gel prepared using natural polymer. Int J Drug Delivery 2010, 2: 58-63.

12. Multimer MN, Riffskin C, Hill JA. J Am Rheological and Mechanical Properties of Pharmaceutical Gels. Medicated Systems-Relevance to Hydration Properties and Drug Release. Boll. Chim. Farm. 2001; 140 (5): 337 -44.

13. Mizushima Y, Kobayashi M. Interaction of anti-inflammatory drugs with serum proteins, especially with some biologically active proteins. J Pharm Pharmacol 1968; 20:169-73. 